monkey; and an account by Hertig, Rock, Adams and Mulligan of four normal and four abnormal human ova ranging in age from the fifth day of development to as little as one day after fertilization. These showed, inter alia, that the human blastocyst is prepared for implantation slightly more rapidly than the monkey egg.

It is odd to think that until relatively recently the number of early human embryos that have been studied was so few that almost each had a name. The enormous increase in the amount of material that has become available for study is a direct consequence of the interest in the whole of this problem that has been generated by the Camegie Department of Embryology. It is also a direct outcome of the researches on reproduction in which the Department has played so big a part, and which have made it possible to estimate when ripe follicles will be present in the ovaries, and when ovulation is likely to occur. Armed with this knowledge, it is possible to time certain types of operation that have to be carried out so as to increase the chances of recovering, for scientific study, the human egg in its first stages of development. The latest chapter of the story is not, however, told in Vol. 35 of the "Contributions". The December 1954 issue of the Transactions of the New York Academy of Sciences, and the February 1955 number of the American Journal of Obstetrics and Gynecology, include articles by Landon B. Shettles describing the in vitro fertilization of the human ovum and its transformation into an eight-cell morula. This is a great technical achievement, and it opens up the possibility of exploring still further some of the most basic problems of human development.

S. ZUCKERMAN

\section{ELECTRICAL PROPERTIES OF WOOD}

$\mathrm{T}$

HE electrical properties of wood are of importance in high-frequency heating processes, in the use of wood as an insulator, and in the determination of moisture content by electrical means. Whereas the direct-current behaviour of wood can be specified solely by the electrical conductivity, the alternatingcurrent behaviour requires two quantities-the relative permittivity (or dielectric constant) $k$, and the loss tangent tan $\delta$-for its specification. In order to assess the effect of frequency, grain direction and moisture content on the dielectric properties of wood, R. F. S. Hearmon and J. N. Burcham have recently measured $k$ and $\tan \delta$ for twelve different species of wood in the three grain directions, at moisture contents up to 18 per cent and more, the frequency range being $2 \mathrm{kc} . / \mathrm{s} .-60 \mathrm{Mc} . / \mathrm{s} . *$. The specimens were in the form of disks, approximately $5 \mathrm{~cm}$. in diameter and $0.6 \mathrm{~cm}$. thick, and tin-foil electrodes were attached to the flat faces with a thin film of 'Vaseline'.

The results for the two species, sitka spruce and oak, representing medium-light and medium-heavy timbers respectively, are presented and discussed in some detail. The permittivities change uniformly with moisture content and frequency, being closely related to the density, and a method is suggested by which the permittivities of any timber may be predicted approximately in terms of the density, moisture content and frequency. The inter-relation-

* Forest Products Research Special Report No. 8: The Dielectric Prortiog iv +20 . (London: H.M.S.O., 1954.) 1s. $6 d$. net. ship between loss tangent and these three quantities is, however, highly complex, and it is not possible to predict values of $\tan \delta$ with any accuracy. A few measurements were made, in addition, on oak of moisture content 75 per cent and on wych elm of moisture content 70 per cent, and although $k$ and tan $\delta$ varied considerably with frequency, the electrical conductivity did not change greatly over the frequency range $1-100 \mathrm{kc}$. $/ \mathrm{s}$. It is concluded that for low moisture contents the results are in accord with the qualitative description of the dielectric behaviour of wood, which can be given in terms of the dipolar mechanism of electrical conduction, but that for high moisture contents the effect of ionic conductivity becomes of greater importance and must be taken into account.

\section{CACAO RESEARCH}

$T$ WHE staff of the Cacao Research Scheme at the Imperial College of Tropical Agriculture, Trinidad, comprises plant breeders, physiologists, soil chemists, a biochemist, a mycologist, an entomologist and estate personnel. The aim of the research programme is to improve the yield and quality of cacao beans, that is, it is essentially of an applied character, such fundamental research as may be undertaken being in direct relation to practical needs. In the Report for 1953 now published (obtainable from Trinidad or from the London Office, 40 Norfolk Street, W.C.2; November 1954; 10s. 6d.) an account is given of research completed, research in progress and research contemplated.

An interesting account is given of the 1952-53 collecting expedition to Colombia. This includes full notes on the different forms of caceo (Theobroma cacao) observed, together with some thirteen other species which were collected, and ten species of the related genus Herrania. This venture also yielded valuable information on the insects, and their parasites and predators, associated with these plants, and on the incidence of the witches' broom and Monilia fungal diseases. Many of the new materials have now been established in Trinidad. A more general result of the expedition has been to support the view that the centre of origin of cacao probably lies near the Colombian-Equadorian frontier on the eastern flanks of the Andes.

Experiments on the effects of shade and fertilizer applications have shown that, as light intensity increases, the trees become more vigorous but, at 75 and 100 per cent light, growth is dependent on fertilizer treatment: in the absence of additional nitrogen the plants are stunted, but with nitrogen they are very vigorous, yielding considerable lateral branching and a closed canopy. The mean yield increases with increasing light intensity up to 50 per cent light; thereafter it decreases progressively. This trend is, however, reversed by nitrogen additions, maximum yields being recorded at 75 per cent light. Light is especially important in determining the duration of the cropping period. At low light intensities there is a steady production of pods but no peak harvest, whereas with 50 per cent light, or more, all pods mature in a peak period. Fertilizer applications both advance the onset of harvesting and yield a distinctive peak as compared with the controls.

A new, effective and relatively cheap technique for the rooting of cacao cuttings has now been suggested. Baskets of soil, with a central core of composted 
sawdust, are prepared and the cutting inserted in the compost, one per basket. The cuttings are then rooted in a shaded glasshouse with controlled humidity at 100 per cent. It is stated that one unit could supply 30,000 plants ready for field planting.

Techniques for the complete study of the contents of a single pod have been taken a stage further by the use of an improved microfermentary. Improvements have also been effected in the solar fermentary, which is of a capacity intermediate between the normal fermentation box (or sweatbox) and the microfermentary.

Other papers in this report are concerned with such topics as physical measurements of soil, the effect of shade and of mulching on soil temperature, nitrogen partition in the normal cacao leaf (as a contribution to an understanding of the rate of development of some pest populations), the susceptibility of various selections to witches' broom disease, spraying against this disease, and various entomological and cultural studies. Researches in progress and those contemplated are also briefly annotated.

\section{MICRO-FOSSILS IN EARLY FLORAS}

A

TTENTION has been directed to the important bearing of certain micro-fossils on our knowledge of the nature and composition of Pre-Carboniferous floras in Canada by N. W. Radforth and D. C. McGregor (Canadian J. Bot., 32, 5, 601 ; 1954).

It has now been ascertained that, in Canada, rocks of Devonian age are associated with the occurrence of oil and gas. In some of these oil-yielding areas, which present serious difficulties to the stratigrapher because of the presence of 'unfossiliferous' sediments, that is, barrenness of plant remains as macro-fossils, it appears that the investigation of the micro-fossils is likely to afford a tool of practical value, and to yield information of very great interest to the palæobotanist; for the Devonian period has long been held to be one of critical importance in the evolution and development of the flora of the land.

Fifty-six recently discovered spores and spore-like micro-fossils from Canadian non-coaly deposits of Middle and Upper Devonian age have now been described and classified by these investigators. The manner of occurrence of these fossils suggests that they may probably be useful in ascertaining biostratigraphical entitios and in the further investiga. tion of oil-bearing rocks.

In relation to the evolution of plants, these microfossils afford evidence of a more complex and more highly evolved Devonian flora than has been apparent from the macro-fossil record. Furthermore, preliminary investigations have disclosed spores of comparable abundance and of only slightly less complexity in rocks of Lower Devonian and Silurian a.ge.

On the preliminary evidence now presented, that is, of the existence of large and diversified spore populations in different strata, even in those of Lower Devonian and Silurian age, it appears that the land flora of the Devonian period was both varied and extensive, this being contrary to the commonly held view. The discovery of relatively complex microfossils in Silurian rocks containing Monograptus is important from the botanical point of viow : it indicates that the complexity of form and structure which are normally associated with the vascular plants probably came into existence very much earlier than has usually been assumed, that is, on the evidence derived from the study of such stems, leaves and sporangia as have come to light. Special interest is attached to a Devonian micro-fossil which in appearance resembles angiosperm pollen, though, as the authors are careful to point out, any conclusion about it at this stage would have to be viewed with the greatest caution.

\section{RESPIRATORY PIGMENTS OF RHODOSPIRILLUM RUBRUM}

\author{
By $D_{R}$. BRITTON CHANCE and \\ DR. LUCILE SMITH \\ Johnson Foundation, University of Pennsylvania
}

CENSITIVE spectroscopic methods for recording $\checkmark$ differences of optical density between aerobic and anaerobic suspensions of many types of bacteria have made possible accurate identification of the patterns of their cytochromes, flavoproteins and pyridine nucleotide enzyme systems ${ }^{1}$. We report here a study of the respiratory pigments of Rhodospirillum rubrum, the bacterium in which Duysens ${ }^{2}$ and Vernon and Kamen ${ }^{3}$ have concluded that a cytochrome with an absorption spectrum similar to that of cytochrome $c$ is oxidized in a photochemical reaction.

Spectroscopic changes occurring when the aerobic bacterial suspension became anaerobic were recorded at a series of different wave-lengths from 650 to $390 \mathrm{~m} \mu$ (as in Fig. $1 A$ ) by means of a double-beam apparatus ${ }^{4}$. In each case the difference between the given wave-length and some reference wave-length was recorded ; this eliminated any interference which might have resulted from changes in the lightscattering properties of the bacteria. In some experiments the difference in optical density between two forms of the pigments in two different cuvettes was recorded by means of a split-beam instrument ${ }^{5}$, as illustrated in Fig. $1, B$ and $C$. Photochemical effects upon the spectrum (Figs. 2 and 3 ) were recorded with the same apparatus that was developed for measuring the photodissociation difference spectra of the carbon monoxide compounds of cytochrome oxidases ${ }^{6}$. Here infra-red illumination was obtained from a tungsten lamp through two thicknesses of Wratten $88 \mathrm{~A}$ filter plus Corning 2424. Neutral filters of density between 0.5 and 2.0 were also added until the observed effect of illumination of aerobic cells was very small, similar to that illustrated in Fig. $3 \mathrm{~A}$. The bacteria were obtained through the kindness of Dr. M. D. Kamen and were grown as described by him $^{7}$, except that tap water and twice the concentration of yeast extract and biotin were used. For measurements in the Soret region of the spectrum, cells obtained after two to three days growth were used directly; these had an optical density at $800 \mathrm{~m} \mu$ of about $1.0 \mathrm{~cm} .^{-1}$. Denser suspensions for use in the visible region of the spectmum were obtained by centrifuging the cells, then suspending them in the supernatant fluid.

\section{Dark Reactions of the Pigments}

The difference spectra plotted in Fig. $1 A$ and Fig. $2 A$, curves a (difference in optical density 